\title{
Induction of Autotetraploid Plants of Sorghum versicolor
}

\author{
Y. Sun', S. O. Cheng ${ }^{2}$ and G. H. Liang ${ }^{1 *}$ \\ ${ }^{1}$ Dept. of Agronomy, Kansas State University, Manhattan, KS 66506-5501, USA \\ ${ }^{2}$ Sorghum Institute, Shanxi Academy of Agricultural Sciences, \\ Yuci, Shanxi, P. R. China 030600
}

Accepled December 2, 1993

Cultivated sorghum [Sorghum bicolor (L.) Moench, $2 n=20$ ] is an important food and feed crop in the world. To improve its yield and quality, we need not only to use the gene pool of Eusorghum itself but also to explore those from related species. S. versicolor $(2 \mathrm{n}=10)$, originating in Southern Africa, is one of those species. It belongs to the Section Parasorghum of the genus Sorghum. S. versicolor possesses some unique traits that $S$. bicolor lacks. The protein content of $S$. versicolor seed is about $28 \%$ (greenhouse-grown), which is over $150 \%$ more than that of seed of commonly grown $S$. bicolor hybrids (cultivars); trichomes on the abaxial surface of $S$. versicolor leaves are associated with drought tolerance and insect resistance. Transferring these traits into $S$. bicolor is desirable, but no successful wide hybridization between two species has been achieved, although various treatments have been attempted, including reciprocal pollinations, $\mathrm{GA}_{3}$ treatment after pollination, style pollination, and in vitro pollination (Garber 1950, Sun et al. 1991).

Johnston et al. (1980) and Sangduen and Hanna (1984) have hypothesized that an endosperm balance number (EBN) is very important in achieving wide crosses. A ploidy ratio of $2: 3: 2$ for embryo: endosperm : maternal tissue is believed essential for normal hybrid seed development. Therefore, wide crosses between $S$. bicolor and $S$. versicolor with equal chromosome numbers might be more successful. Thus, availability of 20 chromosome $S$. versicolor might be useful in obtaining a species hybrid. Furthermore, studying chromosome behavior, seed set, and performance of other traits of progenies of autotetraploid $S$. versicolor would improve our understanding of autotetraploidy. The purposes of this study were to double the chromosome number of $S$. versicolor as a basis for further research on species hybridization between $S$. bicolor and $S$. versicolor and to examine chromosome behaviors and morphological variations of the induced autotetraploid plants.

Colchicine is the most widely used agent to induce autopolyploid plants. Various plant parts can be exposed to the treatment. The most influencial factors in the treatment are species, plant organs, concentration of the solution, duration, and temperature of the treatment (Poehlman 1979, Niu et al. 1982, Ronald and Paul 1984). Our study was designed to reveal the effects of colchicine treatments during seed germination, seedling development, and blooming stages.

In general, autopolyploid plants are stockier than the original diploids. Their stems are thicker and stouter; leaves are thicker, larger, and deep green in color and roots, flowers, and seeds are larger. In some species, autopolyploids show more growth vigor and more tolerance to certain diseases and insects, but their fertility (seed set) is always low (Poenlman 1979).

Materials and methods

1. Seed treatment. Seeds from $S$. versicolor were germinated on a piece of blotting paper 
in Petri dishes. The paper was saturated with $0.01 \%$ colchicine solution, and the dishes were placed in darkness for 5 days. Then the germinating seeds were removed and rinsed with tap water for $1 \mathrm{hr}$. The seeds were transferred to blotting paper saturated with tap water and placed on a lab bench under room light. When the treated seeds produced shoots of 3 to $5 \mathrm{~cm}$ in length, they were transferred into pots and grown in a greenhouse. The temperature for seed germination was $24^{\circ} \mathrm{C}$.

2. Treatment at seedling stage. Seeds were germinated under room temperature on blotting paper saturated with tap water. When their shoots reached to $3-5 \mathrm{~cm}$ long, they were treated with colchicine solution at concentrations of $0.05 \%, 0.1 \%$, and $0.2 \%$. Apical meristems, root tips, and whole seedlings were treated individually. A total of nine combinations ( 3 seedling organs $\times 3$ colchicine concentrations) were used in the experiment with three replications for each combination. The seedling parts were submerged in beakers containing the colchicine solutions supplemented with air bubbling. After treatment for $6 \mathrm{hr}$, the seedlings were rinsed in tap water for $1 \mathrm{hr}$ and transferred to plastic pots containing vermiculite. The pots were placed in darkness for $24 \mathrm{hr}$, then transferred into a growth chamber with $12 \mathrm{hr}$ light. When shoots reached about $10 \mathrm{~cm}$ in length, seedlings were transferred into pots with soil and grown in a greenhouse.

3. Panicle treatment. Panicles of $S$. versicolor after anthesis were treated with $0.1 \%$ colchicine solution. The panicles were trimmed so that only florets at the same blooming stage were treated. The trimmed panicles were submerged in test tubes filled with the colchicine solutions. Durations of treatment were 12,18 , and $24 \mathrm{hr}$, respectively. Seeds from the treated panicles were grown in a greenhouse. Temperatures of greenhouse and growth chamber ranged between 25 and $33^{\circ} \mathrm{C}$.

Morphological changes indicated previously (Poehlman, 1979, Niu et al. 1982) were used as indicators for visual selection of chromosome-doubled plants in our experiments. The selections based on morphological changes were then verified by cytological observations following the method of Tang and Liang (1987). Seed set was recorded as ratio of number of seed to number of florets for each plant. A section of inflorescence from each plant was fixed in Carnoy's A solution (3 95\% EtOH : 1 acetic acid). Twenty pollen mother cells at prophase I or metaphase I were chosen randomly and examined for various pairing configurations, and another 20 cells at anaphase I were chosen randomly to determine unequal chromosome distribution. Cytological observations were made with an Olympus BH-2 microscope equipped with a phase contrast ocular lens. Microphotograghs were taken with Technical Pan film (100 ASA). Statistical tests were made with SAS.

\section{Results}

All treatments produced chromosome-doubled plants with various efficiencies.

1. Seed treatment. Seeds treated with colchicine solution germinated more slowly than the controls germinated in tap water. Primary root tips and mesocotyls of some germinating seeds were enlarged. After the colchicine was rinsed off, primary roots produced some new branch roots. Some treated seedlings recovered gradually in greenhouse, and many died. Out of 150 treated seed, 99 germinated, of which root-tip enlargement was observed in 67 seedlings, and 40 died at the seedling stage. Based on the morphological and cytological changes, we identified 10 autotetraploid plants, or a production rate of $6.6 \%$. We marked the seedlings that had the root-tip and mesocotyl enlargements and found that only the seedlings with enlargements produced tetraploid plants, so seedlings that did not show enlargement could be discarded in an early growth stage.

2. Treatment of seedlings. After colchicine treatment, enlargement of the mesocotyl 
appeared on some seedlings in 3 to 5 days. In a total of 540 treated seedlings, 273 died before heading. The whole-seedling treatment with $0.1 \%$ colchicine was most effective (Table 1 ). It produced $8.3 \%$ tetraploid plants, which was the highest of all treatments and significantly

Table 1. Number of tetraploid plants induced from colchicine-treated $S$. versicolor seedlings

\begin{tabular}{lcccc}
\hline \hline Treated organs & Colchicine concen. & Treated seedlings & Tetraploid plants obtained & Production rate $(0 \%)$ \\
\hline Shoot & 0.05 & 60 & $0^{\mathrm{d}}$ & 0 \\
& 0.1 & 60 & $2^{\text {bcd }}$ & 3.3 \\
Root & 0.2 & 60 & $4^{\mathrm{ab}}$ & 6.7 \\
& 0.05 & 60 & $0^{\mathrm{d}}$ & 0 \\
Whole & 0.1 & 60 & $2^{\text {bcd }}$ & 3.3 \\
scedling & 0.2 & 60 & $1^{\text {cd }}$ & 6.7 \\
& 0.05 & 60 & $4^{\mathrm{ab}}$ & 8.3 \\
\hline
\end{tabular}

"Numbers followed by same latter are not significant at 0.05 level of LSD.

Table 2. Total numbers of seeds and tetraploid seeds in panicles treated with colchicine

\begin{tabular}{cccc}
\hline Time of treatment & Number of treated florets & Number of seeds (\%) & Number of tetraploid seeds ( $\left.{ }^{0} 0\right)$ \\
\hline $12 \mathrm{hr}$ & 198 & $13(6.6)$ & $2(1.0)$ \\
$18 \mathrm{hr}$ & 269 & $12(4.5)$ & $2(0.74)$ \\
$24 \mathrm{hr}$ & 209 & $5(2.4)$ & $1(0.48)$ \\
\hline
\end{tabular}

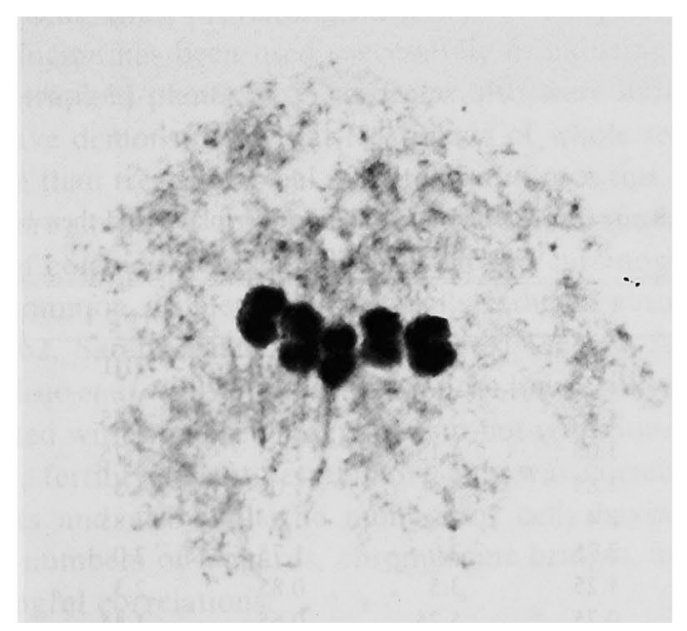


higher than five of the nine treatments.

3. Panicle treatment. Colchicine-treated panicles were harvested after they reached maturity. Seed set on each panicle was recorded, harvested seeds were germinated, and root-tips of the germinating seeds were taken for further cytological observation. Of 30 harvested seeds, 5 tetraploids were identified. We noticed that seed set was reduced with an increase in treatment time (Table 2). Seed set of the treated panicles varied between $2.4-6.6 \%$, and induced tetraploid seed varied between 0.48 and $1 \%$. Because the percentages of seed set

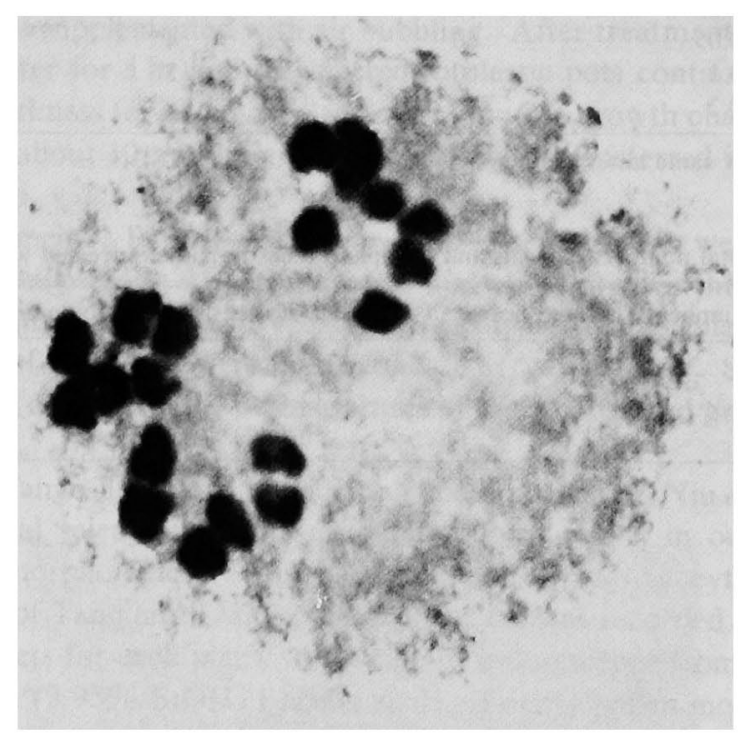

Fig. 2

Table 3. Seed set of autotetraploid $S$. versicolor plants and their behaviors in meiosis of pollen mother cells

\begin{tabular}{|c|c|c|c|c|c|c|}
\hline \multirow{2}{*}{ Entry } & \multirow{2}{*}{ Seed Set $(\%)$} & \multicolumn{4}{|c|}{ Number* of } & \multirow{2}{*}{ Unequal distribution cells** } \\
\hline & & I & II & III & IIII & \\
\hline CT -7 & 31.2 & 1.45 & 5.05 & 0.75 & 1.55 & 12 \\
\hline CT-18 & 32.6 & 1.05 & 4.15 & 1.05 & 1.75 & 12 \\
\hline CT -36 & 24.8 & 1.85 & 4.5 & 1.05 & 1.5 & 12 \\
\hline CT -45 & 19.0 & 2.4 & 2.85 & 1.5 & 1.85 & 15 \\
\hline CT -49 & 13.5 & 2.75 & 2.0 & 1.75 & 2.0 & 15 \\
\hline CT-66 & 0 & 1.25 & 3.5 & 0.85 & 2.3 & 17 \\
\hline CT -72 & 26.9 & 0.75 & 5.75 & 0.65 & 1.45 & 14 \\
\hline CT-8I & 5.1 & 2.0 & 1.7 & 1.4 & 2.6 & 16 \\
\hline CT -87 & 0 & 2.55 & 1.4 & 1.55 & 2.5 & 16 \\
\hline CT-99 & 17.9 & 1.95 & 2.95 & 1.25 & 2.1 & 13 \\
\hline
\end{tabular}

* Means for 20 cells.

** Numbers of cells with unequal chromosome distribution in 20 cells. 
and tetraploid seeds were so low, no attempt was made to estimate their statistical significance.

4. Morphological observations. The most prominent morphological changes of autotetraploid plants were the increase in seed size and the reduction in fertility. Thousand-seed weight increased from $7.8 \mathrm{~g}$ in diploid plants to $11.3 \mathrm{~g}$ in tetraploid plants, an increase of $44.8 \%$. Seed set of tetraploid plants varied between $0-32.6 \%$. The glume size and lengths of stigmas and anther also increased accordingly. An increase of pollen diameter in autotetraploid plants over their diploid counterparts was significant at the $\mathbf{P}=0.1$ level, but not at the $\mathbf{P}=0.05$ level. Greenhouse observations also showed that tetraploid plants had longer vegetative growth periods (103 days vs 84 days) and were taller $(122.6 \mathrm{~cm}$ vs $98 \mathrm{~cm}$ ) than diploids.

About $20 \%$ of autotetraploid plants died before heading. In some treated plants in which chromosome doubling did not occur, we noticed some morphological modifications, such as bushy habit, high sterility, yellowish leaves, and light brown glumes.

5. Cytological observations. In diploid $S$. versicolor plants no abnormal chromosome pairing was observed (Fig. 1). In tetraploid plants, however, quadrivalents, trivalents, bivalents, and univalents (Table 3 ) were observed at prophase I and metaphase I. Unequal chromosome distribution at anaphase I was noticed in a large number of pollen mother cells (Fig. 2, Table 3). Chromosome number in each daughter cell varied between 6 and 14 . Lagging chromosomes, micronuclei, and chromosome bridges were observed in some dividing cells. Numbers of cells with unequal distributions also were recorded (Table 3). After transforming the percentages of seed set of the tetraploid plants into arcsin values, correlation analyses were made between seed set and numbers of various valents and unequal distribution cells. Spearman's rank correlation also was used for those parameters. In both correlation analyses, seed set had a positive correlation with number of bivalents $\left(r=0.67^{*}, r_{s}=0.75^{*}\right)$ but was negatively correlated with number of quadrivalents $\left(r=-0.85^{*}, r_{\mathrm{s}}=-0.84^{*}\right)$ and cells with unequal chromosome distribution $\left(r=-0.88^{*}, r_{s}=-0.89^{*}\right)$.

\section{Discussion}

Colchicine has been known for its function of inhibiting the formation of spindle fibers and cell membranes in plant cells, thus, preventing formation of daughter cells following chromosome duplication. Colchicine has been used successfully in inducing autotetraploid plants in various species. Autotetraploid plants of $S$. versicolor also were induced successfully in this experiment. We also have demonstrated that treatments of whole seedlings and germinating seeds were more effective than treating apical meristems and root tips. In addition, treatments of seeds and seedlings were simpler to implement, and treatment of germinating seeds required a low dosage $(0.01 \%)$ of colchicine, which is expensive and carcinogenic.

Low fertility is a common problem for artificially induced autopolyploid plants. Some researchers (Schertz 1962, Sarada Mani 1987) attributed the low fertility to irregularity of chromosome behavior. Luo et al. (1992) reported that the low fertility of autotetraploid plants of $S$. bicolor was correlated with number of laggards but not with number of quadrivalents. In the case of $S$. versicolor, fertility of autotetraploid plants was correlated negatively with the number of quadrivalents and also with the number of cells having unequal chromosome distribution. However, numbers of laggards, chromosome bridges, and micronuclei were too few to make any meaningful correlations.

Death of tetraploid plants before heading might have been due to physiological disturbances. Morphological changes in treated but nondoubled plants indicated that colchicine could induce mutations. Fertility of the induced tetraploid plants might be increased by natural or artificial selection (Schertz 1962, Luo et al. 1992). In this study, three successive generations of selection did not significantly increase the seed set. 


\section{Summary}

Autotetraploid plants of $S$. versicolor (Anderss.) $(2 n=10)$ were induced by colchicine treatment. Seedling treatment with $0.01 \%$ colchicine solution for $6 \mathrm{hr}$ led to $8.3 \%$ tetraploid plant induction, and seed germination with $0.01 \%$ colchicine solution for 5 days led to $6.6 \%$ tetraploid plant induction. These were considered the most effective and convenient induction methods. Tetraploid S. versicolor plants grew more vigorously, were taller, and had a longer vegetative growth period and larger glumes and seeds compared to their diploid counterparts. Thousand-seed weight was $11.3 \mathrm{~g}$ for tetraploids and $7.8 \mathrm{~g}$ for diploids, indicating a $44.8 \%$ increase for the former. Cytological observations of meiotic configurations revealed that the unequal distribution of chromosomes of tetraploid $S$. versicolor plants was one of the major reasons causing partial sterility of the plants.

\section{References}

Garber, E. D. 1950. Cytotaxonomic studies in the genus Sorghum Univ. Calif. Publ. Bot. 23: 283-361.

Johnston, S. A., den Nijs, T. P. M., Peloquin, S. J. and Hanneman, R. E. Jr. 1980. The significance of genic balance to endosperm development in interspecific crosses. Theor. Appl. Genet. 57: 5-9.

Luo, Y. W., Yen, X. C., Zhang, G. Y. and Liang, G. H. 1992. Agronomic traits and chromosome behaviour of autotetraploid sorghums. Pl. Breed. 109: 46-53.

Niu, T. T., Du, Y. T. Li, T. Y., Zhang, F. Y. and Liu, G. F. 1982. Preliminary report on artificial inducing polyploids in sorghum. Sorghum Res. 2: 10-15.

Poehlman, J. M. 1979. Breeding field crops. AVI Publishing Inc. Westport, Connecticut.

Ronald, G. G. and Paul, M. L. 1984. In vitro colchicine treatment of $4 \mathrm{x}$ blueberries Vaccinium sp. J. Amer. Soc. Hort. Sci. 109(3): $336-338$.

Sangduen, N. and Hanna, W. W. 1984. Chromosome and fertility studies on reciprocal crosses between two species of autotetraploid sorghum. J. Hered. 75: 293-296.

Sarada Mani, N. 1987. Cytological studies of autotetraploid grain sorghum. Cytologia 52: 587-591.

Scheertz, K. F. 1962. Cytology, fertility, and cross morphology of induced polyploids of Sorghum vulgare. Can. J. Genet. Cytol. 4: 179-186.

Sun, Y., Suksayretrup, K., Kirkham, M. B. and Liang, G. H. 1991. Pollen tube growth in reciprocal interspecific pollinations of Sorghum bicolor and S. versicolor. Pl. Breed. 107: 197-202.

Tang, H. and Liang, G. H. 1987. An improved technique for cytological observations and occurrence of polysomatism in sorghum root tips. J. Hered. 78: 51-53. 